\title{
Analysis of dew condensation and related meteorological factors
}

\author{
Xinyue $\mathrm{Zhu}^{1,}$, Yingying $\mathrm{Xu}^{1, \mathrm{~b}^{*}}$ \\ ${ }^{1}$ Key Laboratory of Songliao Aquatic Environment Jilin Jianzhu University, Changchun 130118; \\ aemail: zhuxinyue3366@163.com, bemail:xuyingying.1019@aliyun.com
}

\section{Keywords: Dew condensation; Poplar stick; Meteorological factor; Temperature}

\begin{abstract}
In order to explore the dew condensation phenomenon, the experiment was settled. Getting use of poplar stick during the growing period of 2015(from the end of the Apr. to the middle of the Nov.) in suburb of Changchun City as ground monitors. Through using software of SPSS 19.0 to analyze the data. The conclusion shows that, meteorological factors are closely related to the strength of dew condensation, the dew condensation strength is positively correlated with the relative humidity, dew point temperature, the outdoor temperature and the wind chill, negatively correlated with wind speed, irrelevant with the air pressure.
\end{abstract}

\section{Introduction}

In a clear night a few clouds, no wind or breeze, the ground or ground surface is gradually cooled due to long wave radiation, so that the air close to the ground or the ground surface is also cool, when the temperature drops to the dew point (when the air water vapor content is constant, the pressure is certain, the temperature dropped to the air reaches saturation temperature known as the dew point temperature, referred to as the dew point) [1]the following, water vapor in the air in the ground or surface condensation to form dew[2].

In the desert[3], tropical rain forest[4], urban[5] and wetland ecosystems[6], water cycle, there are differences in the way, regional climate and human activities significantly affect the water cycle. In recent years, dew as an essential component of the water cycle has been widely concerned. Dew condensation is a common meteorological phenomenon, although the dew condensation is much less than the rainfall, but its occurrence frequency is high, the duration is long, it is the important water source of plants and animals in the arid and semi-arid area.

The research work of domestic research on dew started late, and more concentrated in the drought[2] and semi drought area[7] of dew monitoring. However, urban dew related research rarely involved, only in the southern individual cities to carry out the work of monitoring [8]. The regional and the limitation of the dew study limit people's exploration of the ecological effect of dew. Urban dew is a source of potential water and humidity that can not be ignored. The foreign country has further study on the city's dew after 1950s.

Dew in the urban ecological system as the input of the water resources can not be ignored, for rich dew data, a better understanding of the dew of importance, this study of Changchun City, the dew condensation correlation with meteorological factors were studied, the dew on the study of urban ecological system condensation rules with important significance.

\section{Methods and materials}

In Changchun City of Jilin Province (43 degrees north latitude 05 '45 degrees 15'; longitude 124 degrees 18 '127 degrees 05') Jingyue development zone, Jilin Jianzhu University set up observation points, to 2015 in April to November 2015 to carry out daily monitoring. Jilin Jianzhu University is located in the south-east of Changchun City, Changchun city in the northern hemisphere mid latitude north temperate zone, located in the Northeast Plain Chinese urban hinterland, at an elevation of 250 350 meters, the north temperate continental monsoon climate zone. Jilin Jianzhu University campus for the monitoring of the site, no significant pollution sources around, fewer people, can be used as a representative of the city of Changchun. 
At present, there is no unified standard for urban dew monitoring methods. Dew monitor according to the difference of underlying surface species diversity, this paper mainly discusses the City suburb of green plants and dew condensation strength. Therefore the selection of poplar stick as a collector[9], can more truly reflect the different underlying surface dew condensation, and regular shape, easy to calculate the surface area and scattered dew is not easy, easy to carry. Poplar stick polished into $18 \times 3.5 \times 4.0 \mathrm{~cm}$ (length $\times$ width $\times$ height). The observation frame is made of stainless steel, and there are three height of observation and erection: the base of the plant $(5 \mathrm{~cm}$ up the ground); the canopy of the plant( $25 \mathrm{~cm}$ up the ground); the top of the plant $(50 \mathrm{~cm}$ up the ground), each layer is provided with a monitoring arm.

2015 plant growth period (from the end of the Apr. to the middle of the Nov.) in the green area to set up the observation frame, in a clear night to observe the green area. Experimental within $30 \mathrm{~min}$ after sunset will be accurate weighing monitoring green area monitor (poplar stick) were placed in frames with different height to the observational arm observations, each highly placed three monitor; and before sunrise within 30 minutes will take the monitor under, the monitor into the sealing good clean plastic box, immediately transferred to the laboratory weighing (balance accurate to $0.0001 \mathrm{~g}$ ). If the monitor has weight gain that day there was a layer of dew condensation events, denoted as a dew days, increase the weight is dew condensation of water amount, or that the day without the occurrence of dew condensation events, denoted as no dew days.

In order to express the dew condensation ability, with dew intensity (1) to define land (including plants and soil) someday dew amount, can be calculated in accordance with the following formula:

$$
I=\frac{10 \times\left(W_{r}-W_{s}\right)}{S}
$$

Formula (1) in the $I$ for the dew intensity $(\mathrm{mm}) ; W_{r}$ for the collector to collect dew weight $(\mathrm{g})$; $W_{s}$ for the collector's initial weight $(\mathrm{g}) ; S$ for the collector's specific surface area $\left(\mathrm{cm}^{2}\right)$; 10 for the conversion factor.

The MK-III-LR wireless automatic weather station (USA, Rainwise) is installed in the ground level of the green land area. Install cc-3000 Rainwise version View Weather 32 software on the computer, receive the data of the weather station. Meteorological station mainly receives the following data: relative humidity, external temperature, dew point temperature, atmospheric pressure, wind speed, wind direction, wind, precipitation, solar radiation. The data is recorded once every minute. Due to the formation of dew is affected by various meteorological factors, so the relationship between dew intensity and meteorological factors. Statistical analysis was performed using SPSS 19.0 software.

\section{Discussion on the related factors of dew intensity}

As is shown in the figure, the ground dew strength represents the strength of the plant dew, showed that the difference of underlying surface has a certain effect on the strength of the dew. Plant dew strength in August the strongest, in addition to April, November, the weakest in May; ground dew intensity of the strongest in August, the weakest in September.

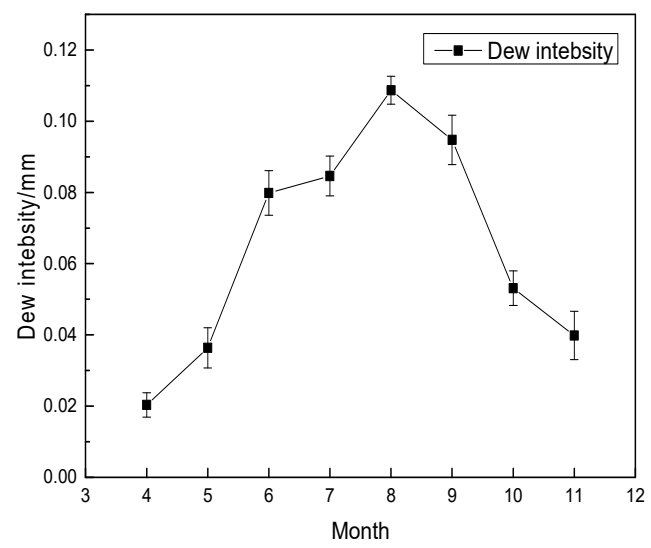

Fig.1. The variety of dew intensity of the ground in Changchun 
Based on the SPSS 19.0 software, the dew intensity of the plants on the outskirts of Changchun city in 2015 and the meteorological factors in the area were collected in 2015. The correlation analysis (Person correlation) was carried out, result representation: the dew condensation strength is positively correlated with the relative humidity, dew point temperature, the outdoor temperature and the wind chill, negatively correlated with wind speed, irrelevant with the air pressure.This is consistent with the findings of Ye et al[10]、 Li[11] et al. Relative humidity for air moisture content, high humidity, indicate that the air in the water vapor is abundant, is conducive to dew condensation, whereas, dew condensation amount is small. When the outdoor temperature drops to the dew point temperature, began to appear dew, the dew point temperature is higher, the lower the outdoor temperature, the greater the dew condensation. The positive and negative effects of wind speed on the formation of dew. Changchun is a continental monsoon climate, when the wind speed is large, easy to water vapor in the air was blown away by the wind and the temperature drop of dew point, moisture to evaporate, is not conducive to the dew condensation; as wind speed is small, is conducive to cooling condensation surface and bring moisture, easy to form dew. Therefore, the change of meteorological factors has a decisive effect on dew condensation.

\section{Test results}

From the above we can know, the ground plant dew strength in August the strongest, weakest in May. Since April and November data is less, do not have convincing, the main analysis of the data from October to May. As shown in the figure, August maximum relative humidity, dew point temperature and the outdoor temperature difference between the minimum wind speed is weak, cold high; meteorological data for may coincided with October instead, relative humidity is minimal. Dew point temperature and the outdoor temperature difference between the biggest the strongest winds, cold is low.
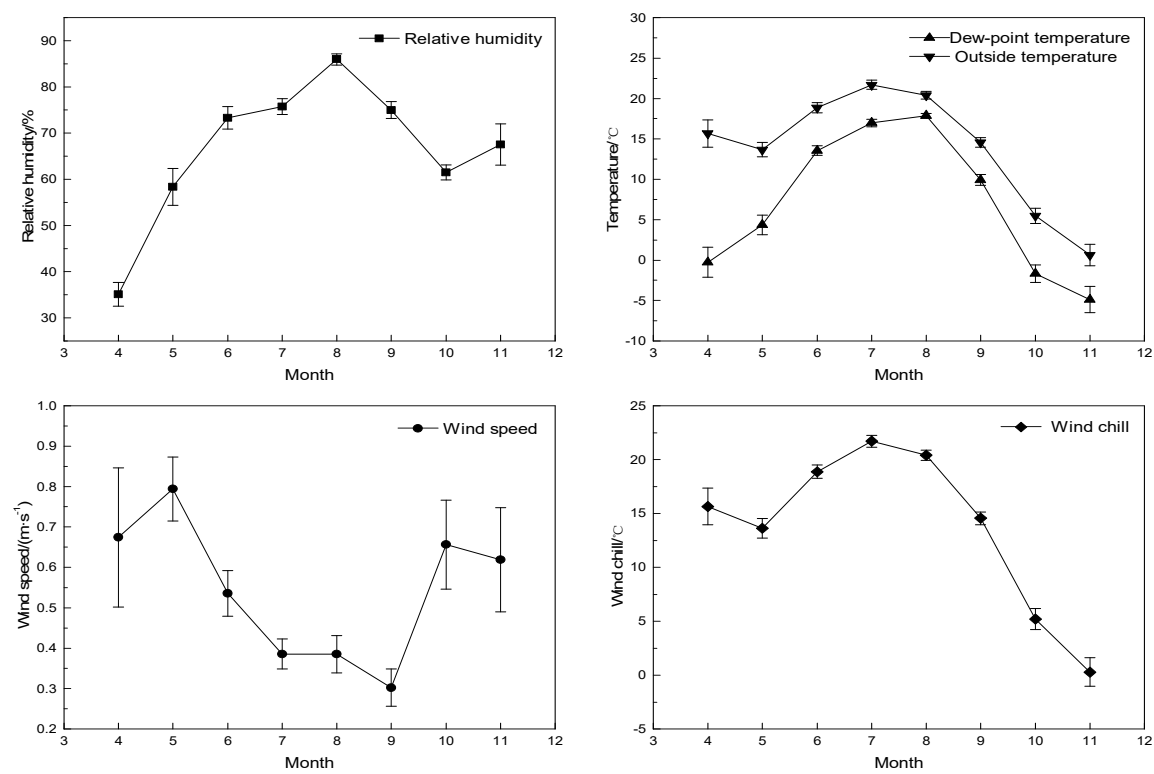

Fig.2. Meteorological data of each month in Changchun

\section{Conclusion}

The data show Changchun dew intensity reached the peak in August. In the data analysis of dew intensity and meteorological factors, found that the meteorological factors have significant influence on dew intensity, through further analysis of the meteorological factors can be concluded. Dew intensity and relative humidity, dew point temperature, outdoor temperature and wind chill was positively related, and the wind speed was negatively correlated with pressure has nothing to do. 


\section{Acknowledgement}

We gratefully acknowledge funding support from the Science and Technology Research Project of Jilin province Department of Education (2016161). National Nature Science Foundation of China (41401229). College Students Innovative Entrepreneurial Training Program (201510191025).

\section{References}

[1] Kozlowski T T. Water Deficits and Plant Growth[M]. New York: Academic Press, 1984: 1-20.

[2] WMO. International Meteorological Vocabulary[M]. Geneva: World Meteorological Organization, 1966: 276.

[3] Abraham Zangvil. Six years of dew observations in the Negev Desert,Israel[J]. Journal of Arid Environments, 1996, 32: 361-371.

[4] Victor L.Barradas, M. Guadalupe Glez-Medellin. Dew and its effect on two heliophile understorey species of a tropical dry deciduous forest in Mexico[J]. International Journal of Biometeorology, 1999, 43(1): 1-7.

[5] Richards K. Urban and rural dew fall, surface moisture, and humidity measurements for Vancouver, Canada[J]. Boundary-Layer Meteorology, 2005, 114: 143-163.

[6] Xu Yingying, Yan Baoxing, Guo Yuedong. Measurement and Analysis of Formation Conditions of Dew in marsh[J]. Wetland Science, 2009, 7(2): 156-161.

[7] Wang Sheng, Zhang Qiang. Atmospheric physical characteristics of dew formation in semi-arid in loess plateau[J]. Acta Physica Sinica, 2011, 60(5): 1-8.

[8] Ye Youhua, Zhou Kai, Peng Shaolinm,et al. Dew condensation in clear night of Conghua city[J]. Tropical geography, 2009, 29(1): 26-30.

[9] Yan Baixing, Xu Yingying, Wang Lixia. Dew condensation rules in farmland ecosystem in Sanjiang plain[J]. Acta Ecologica Sinica, 2010, 30(20): 5577-5584.

[10] Ye Youhua, Zhou Kai, Song Liying, et al. Dew amounts and its correlations with meteorological factors in urban landscapes of Guangzhou, China[J]. Atmospheric Research, 2007, 86: 21-29.

[11] Li Xiaoyan. Effects of gravel and sand mulches on dew deposition in the semiarid region of China[J]. Journal of Hydrology, 2002, 260: 151-160. 